\title{
Nekrolog. Carl Jakob Sundewall $†$.
}

Professor C. J. Sundewall vollendete, nach längerem Krankenlager, in einem Alter von 73 Jahren, am 5. Februar 1875, seine irdische Laufbahn. Geboren am 22. October 1801 in Högestadt bei Ystad, wurde er 1817 Student in Lund, Philosophiae Dr. 1823, Docent 1826, Medicinae Dr. 1830. Bestritt die Professur der Zoologie in Lund 1830-1831, und als Adjunct 1836. Wurde 1839 zum Intendanten des naturhistorischen Reichsmuseums in Stockholm berufen, und erhielt bei der Theilung der verschiedenen Fächer 1841 die Abtheilung der Wirbelthiere, und in demselben Jahre die Stelle als erster Intendant. R. N. O. R. d. fr. E. L. Unternahm wissenschaftliche Reisen: 1821 nach Bohuslan, 1823 nach Dänemark, 1824 nach Oeland, Gotland und Blekinge, 1827-28 auf Veranstaltung des verstorbenen Freiherrn Axel Gyllenkrok nach Ostindien, 1838 mit der französischen Corvette "La Recherche“ nach Spitzbergen, 1841 nach Frankreich, Deutschland und Holland, 1846 nach Norrland und Norrbotten, 1847 nach England, Holland u. s. w. Er war einer der Fünf, welche 1830 den Akademischen Verein in Lund stifteten, und betheiligte sich lange und thätig an dessen Leitung. Seit 1839 war er Mitglied der schwed. Akademie der Wissenschaften; ausserdem Mit- und Ehrenmitglied vieler inund ausländischer wissenschaftlicher Akademien und Gesellschaften. Hat im Drucke herausgegeben eine grosse Anzahl Abhandlungen über seine Wissenschaft, Berichte über die Fortschritte derselben u. s. w., die theils in den Verhandlungen der Akad., theils in Zeitschriften, theils auch besonders gedruckt wurden.

Professor Carl Sundewall war eine ungewöhnliche Persönlichkeit; genau gekannt nur von Wenigen, und von diesen hochgeachtet, sonst wenig bemerkt; einer der berühmtesten Gelehrten Schwedens und auf seinem eigentlichen Felde einer der Ausgezeichnetsten unsrer Zeit. Zwischen seiner ersten 1823 gedruckten Schrift: "Genera Araneidum Sueciae“" und den letzten Aufsätzen*), von welchen er noch auf dem Krankenbette die Correctur las, liegt ein halbes Jahrhundert ununterbrochener und vielseitiger Arbeit, wovon 32 Jahre unserm Reichsmuseum gewidmet waren. Zahlreiche Abhandlungen über naturhistorische Gegenstände, von kurzen Aufsätzen bis zu ausgearbeiteten Monographien und umfassenden, systematischen Uebersichten, die Früchte vieljähriger Studien, geben Zeugniss von seiner hohen Begabung als Naturforscher; ein immer waches Beobachtungsvermögen, eine Selbstständigkeit, die nichts auf Glauben hin annahm, ein starkes und klares Gedächtniss, welches im Stande war, unzählige Einzelnheiten zusammen zu halten, ein Scharfsinn, welcher deren gegenseitige Analogien, selbst die entferntesten, lebendig auffasste und in Ueber-

*) 1. Spetsbergens foglar und 2. Ny anordning af de Trastartade Foglarna (Neue systematische Aufstellung der drosselartigen Vögel) (Oscines Cichlomorphae). Mitgetheilt am 11. März 1874. 
einstimmung damit ordnete; eine prunklose Ehrlichkeit, welche nicht von dem zufällig Glänzenden verlockt wurde, und dabei ein feiner Sinn für das Richtige im Ausdruck, erzeugt durch die Art und Weise seiner Studien, und der sich in seinen Schriften durch die einfache Anmuth der Darstellung vielfach kund giebt. Und diese Eigenschaften, welche auch $\mathrm{zu}$ vielen anderen nicht rein naturhistorischen Arbeiten, zu vielseitigen Sprachstudien, darunter sorgfältige fonographische Untersuchungen, ausreichten, wurden im reichsten Maasse bei der Verwaltung der ihm anvertrauten Abtheilung des zoolog. Reichsmuseums entwickelt, welches für den hohen Standpunkt, den dasselbe neben ähnlichen Instituten einnimmt, Sundewall's grossem ordnendem Geiste zu danken hat, seiner eifrigen, kenntnissreichen Sorgfalt bei der Wahl von neuen Gegenständen, so wie seiner aufopfernden Uneigennützigkeit, womit er willig die oft nicht unbedeutenden Ausgaben, die von dem jährlichen Staatsbeitrage nicht gedeckt werden konnten, als seine eigenen übernahm. Die Quelle einer solchen Thätigkeit war nicht blos in der reichen Begabung des Verstandes zu suchen, sie hatte noch eine andere in einer seltenen Reinheit und Festigkeit des Charakters, in einem starken Willen, welcher jede störende Beschäftigung von sich entfernt hielt und sich ungetheilt dem Beruf und der Pflicht widmete.

Es lag auch über dem ganzen Wesen des einsamen Mannes ein eigenthümlicher Ausdruck von Ernst und Strenge. Aber im Hintergrunde des Ernstes bemerkte man, besonders ehe das Alter kam, einen stillen Humor und ein lebendiges Gefühl für das Schöne; hinter der Strenge, welche grosse Forderungen an seine eigene Kraft, und nicht geringe an die Anderer stellte, lag eine wohlwollende Neigung, wirkliches Verdienst anzuerkennen und zu rühmen und dieses mit wahrem Interesse zu umfassen; und neben einer Sparsamkeit, welche mit einer gewissen Härte manche im Allgemeinen vollberechtigte Lebensbedürfnisse verschmähte, wohnte im Herzen eine Güte, welche in unaufgefordertem Wohlthun und hochsinniger Freigebigkeit einen stillen Ausdruck fand. - Von der Natur war Professor Sundewall mit einem starken Körperbau ausgerüstet, und es kann wohl kaum bezweifelt werden, dass die Kränklichkeit der letzten Jahre in nicht geringem Grade ihren Grund in einer Thätigkeit hatte, die ihm noch im hohen Alter allzugrosse Entbehrungen auferlegte und keine Ruhe gönnte. Sein Tod wird nicht nur von seinen persönlichen Freunden, sondern auch von zahlreichen Mitbrüdern in seiner Wissenschaft betrauert, sowohl in seinem Heimathslande als in der ganzen gebildeten Welt. Unter schwedischen Naturforschern ist sein Name unvergänglich. 


\section{$2 \mathrm{BHL}$ Biodiversity Heritage Library}

1875. "Nekrolog. Carl Jakob Sundewall." Journal

fu

r Ornithologie 23, 214-215. https://doi.org/10.1007/bf02008948.

View This Item Online: https://www.biodiversitylibrary.org/item/101688

DOI: https://doi.org/10.1007/bf02008948

Permalink: https://www.biodiversitylibrary.org/partpdf/141415

\section{Holding Institution}

Smithsonian Libraries

\section{Sponsored by}

Biodiversity Heritage Library

\section{Copyright \& Reuse}

Copyright Status: Public domain. The BHL considers that this work is no longer under copyright protection.

This document was created from content at the Biodiversity Heritage Library, the world's largest open access digital library for biodiversity literature and archives. Visit BHL at https://www.biodiversitylibrary.org. 